\title{
Interações entre fungos micorrízicos arbusculares, rizóbio e actinomicetos na rizosfera de soja ${ }^{1}$
}

\author{
Marsílvio G. Pereira ${ }^{2}$, Carolina E. R. S. Santos ${ }^{3}$, Ana D. S. de Freitas ${ }^{3}$, \\ Newton P. Stamford ${ }^{3}$, Gewerlys S. D. C. da Rocha ${ }^{4}$ \& Alessandro T. Barbosa ${ }^{4}$
}

\begin{abstract}
RESUMO
Isolados de actinomicetos e de fungos micorrízicos arbusculares foram avaliados em sistemas de inoculação conjunta in vivo, em plantas de soja inoculadas com rizóbios, com a finalidade de se observar interações microbianas. A pesquisa foi realizada no Centro Nacional de Pesquisa de Agrobiologia (Embrapa CNPAB). Foram utilizados, como substrato, solo da série Itaguaí (textura média) misturado com areia de rio na proporção 1:1 (v:v), com adição de isolados de actinomicetos (ACT-78 e ACT-370); estirpes de rizóbios (Bradyrhizobium elkanii - BR 29 e Bradyrhizobium japonicum - BR 33) e fungos micorrízicos arbusculares (Gigaspora margarita e Glomus clarum). Os resultados revelam que a inoculação com os fungos micorrízicos arbusculares influenciou de modo expressivo as variáveis de crescimento, nodulação e densidade de actinomicetos na rizosfera de soja, que apresentaram valores maiores do que as plantas sem o inóculo fúngico. Houve efeitos sinergísticos e antagônicos dos fungos micorrízicos arbusculares com os actinomicetos e com rizóbios.
\end{abstract}

Palavras-chave: fixação biológica de nitrogênio, interações microbianas, sinergismo, antagonismo

\section{Interactions between arbuscular mycorrhizal fungi Rhizobium and actinomycetes in the rhizosphere of soybean}

\begin{abstract}
Actinomycete isolates and arbuscular mycorrhizal fungi were evaluated in vivo using jointly inoculation systems with soybean plants inoculated with rhizobia, with the aim to observe microbial interactions. The study was carried out at the National Center of Agrobiologic Research (Embrapa CNPAB). Soil of the Itaguai series (medium texture) was used as substrate mixed with river sand in proportion 1:1 (v:v), adding actinomycete isolates (ACT 78 and ACT 370), rhizobia strains (Bradyrhizobium elkanii - BR 29 and Bradyrhizobium japonicum - BR 33), and arbuscular mycorrhizal fungi (Gigaspora margarita and Glomus clarum). The results revealed the effect of the arbuscular mycorrhizal fungi addition with significant and expressive influence on growth parameters, nodulation and density of actinomycete isolates on the soybean rhizosphere which showed greater values compared with fungi uninoculated plants. Synergistic and antagonistic effects were observed between the arbuscular mycorrhizal fungi with actinomycetes isolates and rhizobia strains.
\end{abstract}

Key words: biological nitrogen fixation, microbial interactions, synergism, antagonism 


\section{INTRODUÇÃO}

O estudo das interações entre os micro-organismos do solo é importante para se compreender a dinâmica dos processos que caracterizam as relações entre o solo e as plantas na biosfera. As pesquisas sobre tais interações biológicas e suas influências no desenvolvimento e na produção de espécies vegetais agrossilvipastoris, têm contribuído na compreensão da biologia da rizosfera e suas implicações no desenvolvimento da agricultura moderna de qualidade e ecologicamente correta.

Entre essas interações as que envolvem rizobactérias e fungos micorrízicos arbusculares (FMA) são de particular interesse em função das interfaces entre o FMA, o solo e a planta, pois os fungos micorrízicos arbusculares se desenvolvem tanto dentro das raízes como fora delas, expandido-se através das hifas, pela rizosfera.

É no ambiente da rizosfera que ocorrem diversas interações microbianas que são muito significativas, de vez que podem modificar a relação entre as plantas e os fungos micorrízicos arbusculares (Fracchia et al., 2004) assim como afetar outros micro-organismos e as interações com as plantas; entretanto, essas interações ainda são pouco estudadas, como as que ocorrem na micorrizosfera, entre os fungos micorrízicos arbusculares (FMA), actinomicetos e rizóbios, na rizosfera de soja.

Os micro-organismos responsáveis pela fixação biológica de nitrogênio (FBN) através da simbiose estabelecida com as plantas leguminosas são as bactérias genericamente conhecidas como rizóbios. Para Santos et al. (2008) atualmente são conhecidos 12 gêneros e 62 espécies de rizóbios e há tendência à ampliação desses números considerando-se que a maioria das leguminosas, sobretudo nas regiões tropicais do planeta ainda não foi estudada; dentre essas bactérias o gênero Bradyrhizobium se destaca por formar nódulos na soja.

O uso do gênero Bradyrhizobium como inoculante é, atualmente, uma tecnologia indispensável para a cultura da soja no Brasil (Zilli et al., 2010). A eficiência desses microorganismos tem possibilitado a obtenção de altos rendimentos de grãos da cultura sem a necessidade de aplicação de nitrogênio mineral (Alves et al., 2003; Zilli et al., 2006).

O sucesso no processo de nodulação após a inoculação com rizóbio é determinado por vários fatores tais como fertilidade do solo e competitividade das estirpes dos inoculantes, avaliadas pela capacidade de sobreviver e colonizar as raízes das plantas em um ambiente com abundância de micro-organismos nativos produzindo nódulos de fixação (Melchiorre et al., 2011). Entre as estirpes de Bradyrhizobium selecionadas para a soja, a melhor capacidade de competir por sítios de nodulação no campo tem sido atribuída à espécie $B$. elkanii (Boddey \& Hungria, 1997; Neves \& Rumjanek, 1997) porém, quanto ao acúmulo de $\mathrm{N}$, tem sido verificada maior eficiência promovida por $B$. japonicum (Neves \& Rumjanek, 1996). Infelizmente, vem sendo difícil estabelecer essas estirpes superiores em solos recém-incorporados ao sistema de produção agrícola ou em solos em que as estirpes resistentes a antibióticos tenham sido introduzidas previamente ou, ainda, devido a problemas de competição com os micro-organismos nativos e/ou pela sua inabilidade de sobrevivência nesses solos.

Diversos fatores abióticos e bióticos podem alterar os padrões de competitividade das estirpes de Bradyrhizobium spp. Entre os fatores bióticos Pereira et al. (1999) destacam as populações de actinomicetos na comunidade microbiana de solos tropicais, pelo potencial dos mesmos em produzir antibióticos pois cerca de $85 \%$ dos antibióticos conhecidos são produzidos por esses micro-organismos (Gottlieb, 1973).

Os antibióticos podem ser produzidos em ecossistemas naturais e agroecossistemas e no solo podem apresentar efeitos antagônicos a diversas populações da comunidade microbiana. Entre esses efeitos antagônicos estão aqueles causados por bactérias do grupo dos rizóbios (Pereira et al., 1999), bactérias diversas resistentes e sensíveis à meticilina (Satheeja \& Jebakumar, 2011), fungos micorrízicos arbusculares (Moreira \& Siqueira, 2006) e aqueles causados sobre o sistema simbiótico rizóbio - FMA - planta (Pereira et al., 1991).

O objetivo deste trabalho é avaliar as interações biológicas na rizosfera de soja envolvendo fungos micorrízicos arbusculares (FMA), rizóbios e actinomicetos isolados de solo de região produtora de soja.

\section{Material e Métodos}

$\mathrm{O}$ estudo foi realizado em casa de vegetação, no Centro Nacional de Pesquisa de Agrobiologia (Embrapa CNPAB), Seropédica, RJ, com $22^{\circ} 46^{\prime}$ de latitude sul e $43^{\circ} 41^{\prime}$ de longitude Oeste, com altitude de $33 \mathrm{~m}$, nos Laboratórios de Ecologia Microbiana e de Micorrizas (Embrapa CNPAB) e no Laboratório de Microbiologia do Solo (DEPA/UFRPE).

Conduziu-se um experimento utilizando-se vasos (capacidade $1 \mathrm{~kg}$ ), sendo o substrato constituído de solo da série Itaguaí (textura arenosa), autoclavado por duas vezes, a $121^{\circ} \mathrm{C}$ e $1.5 \mathrm{~atm}$, misturado com areia de rio na proporção de $1: 1$ (v:v) e distribuído no vaso da seguinte maneira (uma primeira camada de $700 \mathrm{~g}$ do solo autoclavado no fundo do vaso; uma segunda camada de $100 \mathrm{~g}$ correspondente ao inóculo misto de FMA (solo, raízes, hifas e esporos) e uma terceira camada de $200 \mathrm{~g}$ de solo autoclavado. O inóculo de FMA foi incubado durante uma semana.

A análise do solo apresentou as seguintes características (Tabela 1).

Tanto a adubação fosfatada quanto a correção de $\mathrm{pH}$ foram realizadas para um volume de $160 \mathrm{~kg}$ de solo com $32 \mathrm{~g}$ de superfosfato simples e $80 \mathrm{~g}$ de óxido de cálcio, respectivamente. Foram adicionados $6 \mathrm{~g}$ de potássio na forma de $\mathrm{K}_{2} \mathrm{SO}_{4} \mathrm{e}$ uma

Tabela 1. Características químicas e físicas do solo

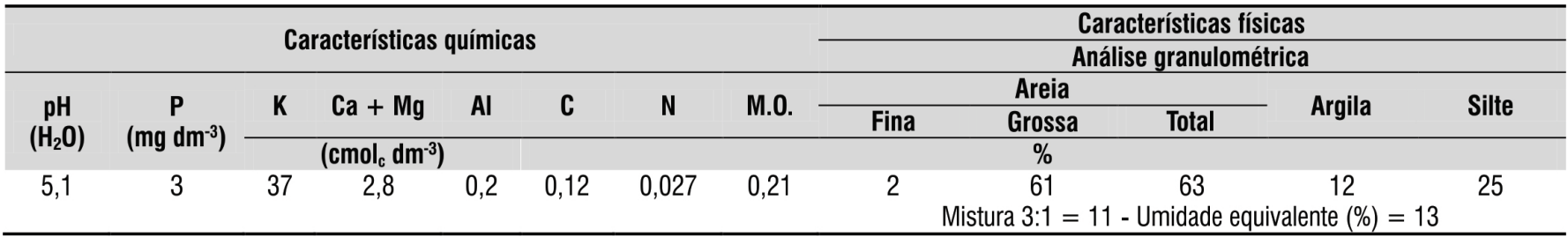


solução nutritiva de micronutrientes e $\mathrm{Mg}$ (Franco \& Döbereiner, 1967) foi adicionada semanalmente na água de irrigação.

Foram utilizados como inóculos, dois isolados de actinomicetos (ACT-78 e ACT-370), identificados como Streptomyces spp.; duas estirpes de Bradyrhizobium (BR 29 de Bradyrhizobium elkanii e BR 33 de Bradyrhizobium japonicum) e duas espécies de fungos micorrízicos arbusculares (FMA): Gigaspora margarita e Glomus clarum, obtidos da coleção de culturas do CNPAB/EMBRAPA. O inóculo das estirpes de Bradyrhizobium foi crescido em meio de cultura líquido descrito por Vincent (1970) (10 ${ }^{8}$ Unidades Formadoras de Colônias $\mathrm{mL}^{-1}$ ) e o inóculo de actinomicetos foi preparado a partir de colônias crescidas em meio amido- $\mathrm{NO}_{3}$ (Waksman, 1961), obtendo-se uma suspensão de inóculo contendo aproximadamente $10^{8} \mathrm{UFC} \mathrm{mL}^{-1}$.

$\mathrm{O}$ inóculo misto das espécies de FMA foi multiplicado em vasos de cultivo com Brachiaria decumbens, contendo aproximadamente 144 esporos por $50 \mathrm{~cm}^{3}$ para Glomus clarum e aproximadamente 266 esporos por $50 \mathrm{~cm}^{3}$ para Gigaspora margarita. O delineamento experimental foi inteiramente casualizado com os tratamentos constituindo um esquema fatorial ( $3 \times 3 \times 3)$ com cinco repetições, totalizando 135 observações. O arranjo experimental teve os seguintes fatores: Fator 1: Tratamentos com Fungos Micorrízicos Arbusculares (FMA): T1-Gigaspora margarita; T2-Glomus clarum; T3-Sem o inóculo fúngico; Fator 2: Tratamentos com Rizóbio: T1-Somente $B$. elkanii; T2 - Somente B. japonicum; T3 - Misto (B. japonicum + B. elkanii) e Fator 3: Tratamentos com Actinomicetos:T1-Isolado ACT - 78; T2 - Isolado ACT - 370; T3 - Sem Actinomicetos.

As sementes de soja (cv. Seridó) foram desinfestadas em álcool $96^{\circ}$ GL por trinta segundos e em peróxido de hidrogênio
(10\%) durante 3 min e sete lavagens consecutivas com água destilada esterilizada.

A coleta do experimento foi realizada aos setenta e quatro dias após sua montagem, época de iniciação da floração da soja e as variáveis avaliadas foram as seguintes: BPAS: (Biomassa da Parte Aérea Seca - g planta-1 ${ }^{-1}$; BRS: (Biomassa de Raiz Seca - g planta $^{-1}$ ); BPAS/BRS: (Relação ou razão entre BPAS/BRS); NNOD: (Número de Nódulos); BNS: (Biomassa de Nódulos Secos - mg planta ${ }^{-1}$ ) e DARS: (Densidade de Actinomicetos na Rizosfera de Soja).

Em geral, a densidade da população de actinomicetos na micorrizosfera foi avaliada pelo método de diluições e contagens em placas. Foram utilizadas, para plaqueamento, as diluições $10^{2}, 10^{4}, 10^{6}$, com três repetições cada uma e, para efeito de avaliação, considerou-se a diluição $10^{4}$.

A densidade da população de actinomicetos foi expressa pelo número de unidades formadoras de colônias (UFC $\mathrm{g}^{-1}$ de raiz seca), obtido após a secagem das raízes em estufa de circulação forçada a $65^{\circ} \mathrm{C}$, até alcançar peso constante.

A análise estatística dos dados foi realizada através da análise descritiva e exploratória e mediante Análise de Variância - ANOVA; para isto utilizou-se, como ferramenta auxiliar, o "PASW® Statistics 18 CoreSystem" ou como é conhecido SPSS.

\section{Resultados e Discussão}

As Tabelas 2, 3 e 4 apresentam os valores do tamanho da amostra, da média e desvio padrão para as variáveis medidas por cada um dos fatores definidos para o experimento.

De acordo com a Tabela 2 e analisando os resultados para o fator 1 (FMA), percebe-se que a presença das espécies de

Tabela 2. Estatísticas descritivas para as variáveis de entrada do estudo, segundo os tratamentos do fator 1 do experimento

\begin{tabular}{|c|c|c|c|c|c|c|c|c|c|c|c|c|c|}
\hline \multirow{3}{*}{ Variáveis } & \multicolumn{9}{|c|}{ Tratamentos com Fungos Micorrízicos Arbusculares (FMA) } & \multirow{2}{*}{\multicolumn{3}{|c|}{ Total }} & \multirow{3}{*}{$\begin{array}{c}\text { Comparação } \\
\text { dos tratamentos } \\
\text { (Valor-p) }\end{array}$} \\
\hline & \multicolumn{3}{|c|}{ Gigaspora margarita } & \multicolumn{3}{|c|}{ Glomus clarum } & \multicolumn{3}{|c|}{ Sem o inóculo fúngico } & & & & \\
\hline & $\mathrm{n}$ & Média & DP & $\mathbf{n}$ & Média & DP & $\mathrm{n}$ & Média & DP & $\mathbf{n}$ & Média & DP & \\
\hline BPAS (g planta-1) & 45 & $2,89^{\text {в }}$ & 0,55 & 45 & $2,79^{\text {в }}$ & 0,73 & 45 & $0,570^{\mathrm{A}}$ & 0,39 & 135 & 2,14 & 1,20 & $0,0000^{(*)}$ \\
\hline BRS (g planta-1) & 45 & $0,53^{\text {в }}$ & 0,11 & 45 & $0,54^{\text {B }}$ & 0,18 & 45 & $0,180^{\mathrm{A}}$ & 0,12 & 135 & 0,43 & 0,21 & $\left.0,0000^{*}\right)$ \\
\hline BPAS/BRS & 45 & $5,58^{\mathrm{B}}$ & 1,41 & 45 & $5,59^{\mathrm{B}}$ & 1,77 & 45 & $3,360^{\mathrm{A}}$ & 1,11 & 135 & 4,90 & 1,78 & $0,0000^{(*)}$ \\
\hline NNOD & 45 & $29,60^{\text {в }}$ & 11,95 & 45 & $27,29^{\mathrm{B}}$ & 11,34 & 45 & $11,080^{\mathrm{A}}$ & 11,18 & 135 & 23,10 & 14,00 & $\left.0,0000^{*}\right)$ \\
\hline BNS (g planta-1) & 45 & $0,14^{\text {в }}$ & 0,04 & 45 & $0,17^{\mathrm{c}}$ & 0,05 & 45 & $0,020^{A}$ & 0,01 & 135 & 0,11 & 0,08 & $\left.0,0000^{*}\right)$ \\
\hline DARS $^{1}$ & 45 & $2,696^{\text {в }}$ & 18,40 & 45 & $2,926^{\mathbf{B}}$ & 23,02 & 45 & $0,744^{\mathrm{A}}$ & 12,24 & 135 & 22,32 & 20,91 & $0,0000^{(*)}$ \\
\hline
\end{tabular}

BPAS - biomassa da parte aérea seca; BRS - biomassa de raiz seca; BPAS/BRS - relação ou razão entre BPAS/BRS; NNOD - número de nódulos; BNS - biomassa de nódulos secos; DARS densidade de actinomicetos na rizosfera de soja

(*) Teste (ANOVA) significativo a nível de 0,05; (1) a densidade de actinomicetos é expressa em UFC g-1 raiz $=$ UFC $\times 10^{5}$. Então, tem-se $\left(2,7 \times 10^{5} ; 2,92 \times 10^{5}\right.$ e $0,74 \times 10^{5}$, respectivamente), para os valores médios da variável DARS na última linha da Tabela. Médias seguidas com letras diferentes na linha são significativamente diferentes

Tabela 3. Estatísticas descritivas para as variáveis de entrada do estudo, segundo os tratamentos do Fator 2 do experimento

\begin{tabular}{|c|c|c|c|c|c|c|c|c|c|c|c|c|c|}
\hline \multirow[b]{2}{*}{ Variáveis } & \multicolumn{9}{|c|}{ Tratamentos com Rizóbio } & \multirow{2}{*}{\multicolumn{3}{|c|}{ Total }} & \multirow{2}{*}{$\begin{array}{c}\text { Comparação } \\
\text { dos tratamentos } \\
\text { (Valor-p) }\end{array}$} \\
\hline & \multicolumn{3}{|c|}{ Somente B. elkanii } & \multicolumn{3}{|c|}{ Somente $B$. japonicum } & \multicolumn{3}{|c|}{ Misto (B. japonicum + B. elkanii) } & & & & \\
\hline BPAS (g planta $\left.{ }^{-1}\right)$ & 45 & $2,14^{\mathrm{A}}$ & 1,14 & 45 & $2,200^{A}$ & 1,31 & 45 & $2,080^{A}$ & 1,17 & 135 & 2,14 & 1,20 & 0,8960 \\
\hline BPAS/BRS & 45 & $4,73^{A}$ & 1,52 & 45 & $5,390^{A}$ & 2,14 & 45 & $4,600^{A}$ & 1,56 & 135 & 4,90 & 1,78 & 0,0855 \\
\hline NNOD & 45 & $27,05^{\mathrm{B}}$ & 11,54 & 45 & $16,350^{A}$ & 12,54 & 45 & $25,870^{B}$ & 15,27 & 135 & 23,10 & 14,00 & $0,0004^{(*)}$ \\
\hline BNS (g planta-1) & 45 & $0,13^{A}$ & 0,08 & 45 & $0,100^{A}$ & 0,07 & 45 & $0,120^{A}$ & 0,08 & 135 & 0,11 & 0,08 & 0,1572 \\
\hline
\end{tabular}

BPAS - biomassa da parte aérea seca; BRS - biomassa de raiz seca; BPAS/BRS - relação ou razão entre BPAS/BRS; NNOD - número de nódulos; BNS - biomassa de nódulos secos; DARS densidade de actinomicetos na rizosfera de soja

${ }^{*}$ ) Teste (ANOVA) significativo a nível 0,05; (1) a densidade de actinomicetos é expressa em UFC g ${ }^{-1}$ raiz $=$ UFC x $10^{5}$. Então, tem-se $\left(2,25 \times 10^{5} ; 1,76 \times 10^{5}\right.$ e $2,63 \times 10^{5}$, respectivamente), para os valores médios da variável DARS na última linha da Tabela. Médias seguidas com letras diferentes na linha são significativamente diferentes 
Tabela 4. Estatísticas descritivas para as variáveis de entrada do estudo, segundo os tratamentos do Fator 3 do experimento

\begin{tabular}{|c|c|c|c|c|c|c|c|c|c|c|c|c|c|}
\hline \multirow{3}{*}{ Variáveis } & \multicolumn{9}{|c|}{ Tratamentos com Actinomicetos } & \multirow{2}{*}{\multicolumn{3}{|c|}{ Total }} & \multirow{3}{*}{$\begin{array}{c}\text { Comparação } \\
\text { dos tratamentos } \\
\text { (Valor-p) }\end{array}$} \\
\hline & \multicolumn{3}{|c|}{ Isolado ACT - 78} & \multicolumn{3}{|c|}{ Isolado ACT- 370} & \multicolumn{3}{|c|}{ Sem Actinomicetos } & & & & \\
\hline & $\mathrm{n}$ & Média & DP & $\mathrm{n}$ & Média & DP & $n$ & Média & DP & $\mathbf{n}$ & Média & DP & \\
\hline BPAS (g planta-1) & 45 & $2,130^{\mathrm{A}}$ & 1,19 & 45 & $2,100^{A}$ & 1,15 & 45 & $2,190^{A}$ & 1,29 & 135 & 2,14 & 1,20 & 0,9384 \\
\hline BRS (g planta-1) & 45 & $0,420^{A}$ & 0,20 & 45 & $0,440^{A}$ & 0,20 & 45 & $0,410^{A}$ & 0,24 & 135 & 0,43 & 0,21 & 0,7868 \\
\hline BPAS/BRS & 45 & $4,940^{\mathrm{A}}$ & 1,90 & 45 & $4,520^{A}$ & 1,21 & 45 & $5,270^{A}$ & 2,09 & 135 & 4,90 & 1,78 & 0,1464 \\
\hline NNOD & 45 & $19,980^{A}$ & 12,87 & 45 & $29,090^{\text {B }}$ & 12,47 & 45 & $20,100^{A}$ & 14,89 & 135 & 23,10 & 14,00 & $0,0018^{(*)}$ \\
\hline BNS (g planta-1) & 45 & $0,110^{\mathrm{A}}$ & 0,07 & 45 & $0,120^{A}$ & 0,08 & 45 & $0,110^{A}$ & 0,07 & 135 & 0,11 & 0,08 & 0,4566 \\
\hline DARS $^{1}$ & 45 & $2,594^{\mathrm{A}}$ & 24,87 & 45 & $2,201^{\mathrm{A}}$ & 19,47 & 45 & $1,858^{A}$ & 16,96 & 135 & 22,32 & 20,91 & 0,2779 \\
\hline
\end{tabular}

BPAS - biomassa da parte aérea seca; BRS - biomassa de raiz seca; BPAS/BRS - relação ou razão entre BPAS/BRS; NNOD - número de nódulos; BNS - biomassa de nódulos secos; DARS densidade de actinomicetos na rizosfera de soja

$\left.{ }^{*}\right)$ Teste (ANOVA) significativo nível de 0,05 ; (1) a densidade de actinomicetos é expressa em UFC g ${ }^{-1}$ raiz $=$ UFC $\times 10^{5}$. Então, tem-se $\left(2,59 \times 10^{5} ; 2,20 \times 10^{5}\right.$ e $1,85 \times 10^{5}$, respectivamente), para os valores médios da variável DARS na última linha da Tabela. Médias seguidas com letras iguais na coluna não diferem estatisticamente entre si

fungos micorrízicos G. margarita e G. clarum influenciou de modo expressivo as seguintes variáveis: BPAS, BRS, BPAS/ BRS, NNOD, BNS e DARS que apresentaram valores maiores do que as plantas sem o inóculo fúngico. Entre essas variáveis destacadas ressalta-se, ainda, que houve uma diferença entre os isolados de FMA, ou seja, para BNS o isolado de G. clarum proporcionou um valor médio maior $(0,17)$ do que $G$. margarita que contribuiu para um valor médio de biomassa de nódulos $\operatorname{secos}(=0,14)$.

De acordo com a Tabela 3 , com a análise para o fator 2 (rizóbio) e com a Tabela $4 \mathrm{com}$ a análise para o fator 3 (actinomicetos), constatou-se que houve apenas influência para a variável número de nódulos (NNOD) respectivamente.

De conformidade com a Figura 1A, a inoculação de FMA proporcionou efeito significativo na BPAS de plantas de soja em relação à testemunha sem inóculo fúngico. Conforme a Figura 1B, quando a soja foi inoculada conjuntamente com o FMA Gigaspora margarita e com a mistura de B. elkanii e $B$. japonicum (média $=3,091$ ) diferenças significativas foram constatadas entre as médias de BPAS em relação às plantas que foram inoculadas conjuntamente com Gigaspora margarita e com a estirpe de Bradyrhizobium elkanii (média = 2,603). A Figura 1B mostra exatamente a evolução das médias da variável BPAS para os tratamentos somente $B$. elkanii, somente B. japonicum e a mistura (B. elkanii e B. japonicum) dentro de cada um dos tratamentos realizados com fungos micorrízicos arbusculares (FMA).

Semelhante ao que foi obtido para a variável BPAS, os resultados referentes à variável BRS mostram que somente o fator 1 foi significativo e importante para distinguir as médias desta variável; mais especificamente, os testes
A.

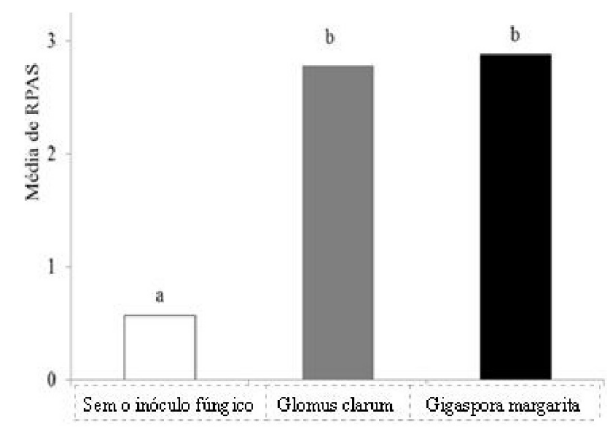

D.

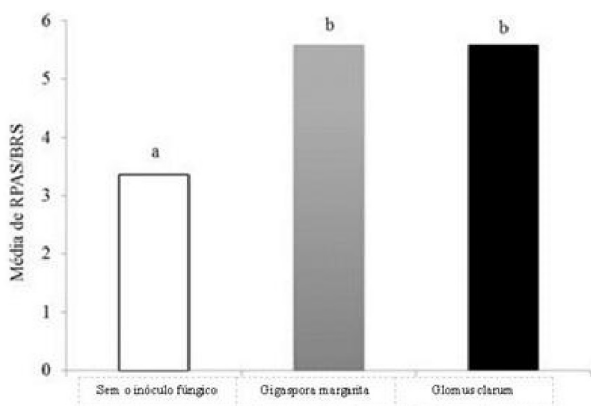

B.

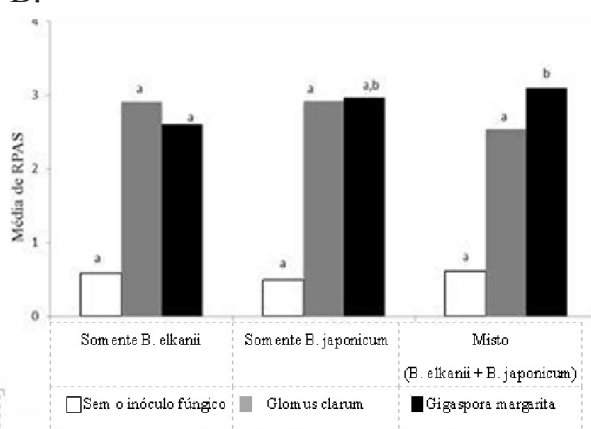

E.

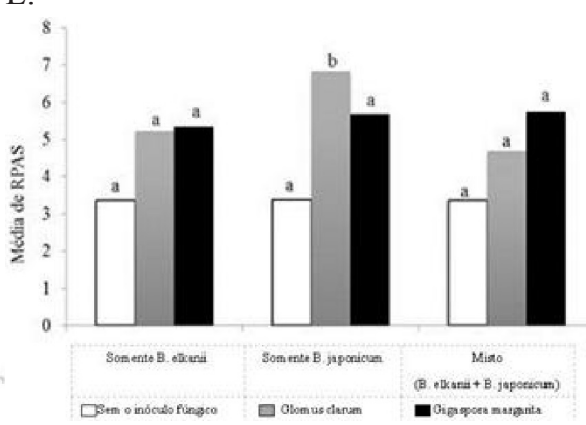

C.

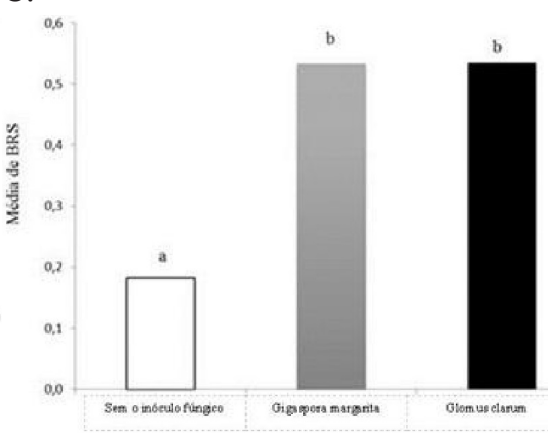

F.

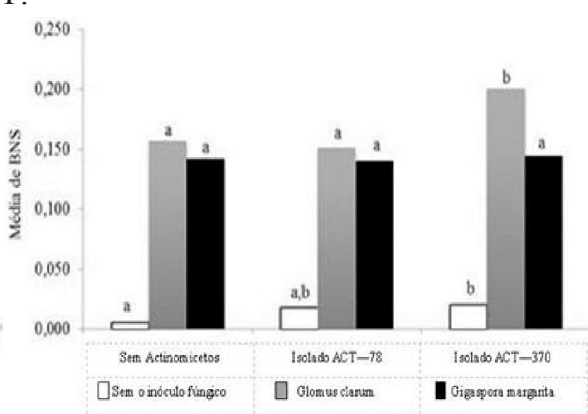

Obs.: Médias seguidas de mesma letra entre colunas de cores diferentes, não diferem entre si pelo Teste de Tukey a 0,05

Figura 1. Comparações múltiplas das médias da variável BPAS para o fator 1 do experimento (A), da variável BPAS para a interação entre os fatores 1 e 2 do experimento (B), da variável BRS para o fator 1 do experimento (C), da variável relação BPAS/BRS para o fator 1 do experimento (D), da variável relação BPAS/BRS para a interação entre os fatores 1 e 2 do experimento (E) e da variável BNS para a interação entre os fatores 1 e 3 do experimento (F) 
de comparações múltiplas (Figura $1 \mathrm{C}$ ) revelaram que a inoculação com $G$. margarita $($ média $=0,534)$ e $G$. clarum $($ média $=0,535)$ teve efeito significativo na BRS de soja em relação às plantas que não receberam o inóculo fúngico (média $=0,182$ ).

Os resultados para a relação entre BPAS/BRS foram muito semelhantes aos encontrados para a variável BPAS, isto é, um modelo final contendo a interação entre os fatores $1 \mathrm{e} 2$. Segundo o teste de comparações múltiplas para o fator 1 (Figura 1D), constatou-se um efeito significativo da inoculação com os dois morfotipos de FMA sobre a variável analisada em relação às plantas sem inóculo fúngico e, para a interação entre os fatores 1 e 2 (Figura 1E), observou-se que apenas as plantas inoculadas conjuntamente com B. japonicum e com Glomus clarum (média $=6,838)$ apresentaram média significativamente diferente dos outros tratamentos. As Figuras 1D e 1E ilustram a evolução das médias da variável BPAS/BRS para o fator 1 e para a interação entre os fatores 1 e 2 , respectivamente.

Conforme os resultados apresentados acima, houve influência da inoculação dos isolados de FMA nas variáveis avaliadas de crescimento e desenvolvimento vegetal (BPAS, BRS e BPAS/BRS) visto que as plantas inoculadas com FMA acumularam maior biomassa vegetal. A influência do fator 1 foi expressiva para a interação com as estirpes de Bradyrhizobium (fator 2) inoculadas simultaneamente; então, as plantas que foram coinoculadas com o FMA G. margarita mais o misto de B. japonicum $+B$. elkanii, cresceram mais e acumularam maior biomassa vegetal de parte aérea em relação à combinação G. margarita e B. Elkanii; já para a relação BPAS/BRS as plantas que receberam o FMA G. clarum + estirpe BR $33-B$. japonicum tiveram uma relação maior entre biomassa de parte aérea e biomassa de raiz acumuladas, em relação à combinação G. clarum + misto de [B. japonicum + B. elkanii]. Tais resultados podem indicar uma interação de cooperação entre o sistema simbiótico tripartite, soja - FMA - Bradyrhizobium spp.

É notória, na literatura, a influência que os fungos micorrízicos exercem sobre efeitos não nutricionais (Moreira \& Siqueira, 2006; Siqueira et al., 2007). De acordo com esses autores, tais efeitos adicionais que contribuem para a melhoria nutricional estão relacionados com a ação biorreguladora da simbiose micorrízica através da produção de estimulantes de crescimento, melhoria na relação água-planta e alterações bioquímicas e fisiológicas. Uma diversidade de compostos e moléculas, como auxinas, citocininas, giberelinas, vitaminas e compostos orgânicos bioativos se acumula em maior quantidade em plantas micorrizadas.

Alguns resultados de pesquisas evidenciaram o efeito benéfico de FMA sobre o crescimento e maior acúmulo de biomassa na parte aérea seca e raiz seca de soja (Vejsadova et al., 1993), o que confirma os resultados deste trabalho. Vejsadova et al. (1993) constataram, investigando a influência da inoculação simultânea de B. japonicum e Glomus claroideum em soja, que a biomassa de raízes foi significativamente maior com a coinoculação citada somente em 4 semanas depois de plantadas e a biomassa de parte aérea seca foi significativamente maior $(+20 \%)$ em plantas micorrizadas em relação ao controle não micorrizado durante a floração das plantas de soja.
O modelo fatorial final para a variável Biomassa de Nódulo Seco (BNS) contemplou todos os fatores individuais, tal como a interação entre os fatores 1 e 3. De acordo com os testes de comparações múltiplas para os fatores individuais, as médias de BNS para os tratamentos envolvendo o fatorl (FMA) são todas diferentes. Portanto, fica evidenciado o efeito significativo da inoculação dos FMA (G. margarita e G. clarum) sobre a biomassa de nódulos secos em plantas de soja cv. Seridó, sugerindo um efeito sinergístico dos FMA sobre as estirpes de Bradyrhizobium sp. (BR 33 e BR 29). Para o fator 2 (Rizóbios), nota-se que a média das plantas que receberam somente a estirpe de B. japonicum (BR 33) foi de $(0,095)$ diferindo estatisticamente das médias dos outros tratamentos deste fator, que foram maiores para BNS, influenciando mais esta variável os tratamentos que receberam a inoculação conjunta de uma mistura de B. japonicum (BR $33)+$ B. elkanii (BR 29) com média igual a $(0,117)$ e somente B. elkanii (BR 29) com média igual a $(0,126)$. Para o fator 3 (actinomicetos) observou-se que a média do isolado ACT - 78 $(0,105)$ difere da média do grupo isolado ACT- $370(0,124)$, mas ambas não diferem do grupo sem actinomicetos, o que denota uma tendência de influência positiva do isolado ACT370 sobre a variável BNS e um efeito negativo do isolado ACT-78 sobre a BNS enquanto as comparações múltiplas do fator 1 avaliadas dentro de cada nível do fator 3, são mostradas na Figura 1F. A análise é semelhante à que foi apresentada no parágrafo anterior, sendo que ela deve ser avaliada dentro de cada tratamento do fator 1 .

A presença ampla dos fungos micorrízicos arbusculares em simbiose com as leguminosas que se associam com o rizóbio para a fixação biológica do nitrogênio, caracterizando um sistema simbiótico tripartite envolvendo planta-FMArizóbio, tem influenciado a nodulação em número de nódulos e em biomassa de nódulos secos, conforme constatado nos resultados descritos acima. Outra influência é sobre a atividade do rizóbio dentro dos nódulos (Barea et al., 2005). Esses processos já são reconhecidos universalmente e nos últimos 50 anos muitos trabalhos de pesquisa têm sido realizados para estudá-los.

Neste sentido, alguns autores têm demonstrado a influência da micorrização na biomassa de nódulos secos, tanto na soja como em outras plantas de interesse agrosilvipastoril (DanielsHylton \& Ahmad, 1994). Esses autores observaram que a inoculação conjunta de FMA e estirpes de rizóbio influenciam no crescimento vegetal, no número de nódulos, peso de nódulos secos, colonização micorrízica e nos teores de $\mathrm{N}$ e $\mathrm{P}$ no fitossimbionte.

A interação entre fungos micorrízicos arbusculares e as estirpes de rizóbio é um típico exemplo de sinergismo entre micro-organismos rizosféricos (Azcón \& Barea, 1996). Em um estudo, Nambiar \& Anjaiah (1989) observaram, em plantas de amendoim, que a presença de FMA (Acaulospora laevis ou Glomus fasciculatus) altera a taxa de nódulos formados por estirpes inoculadas em mistura e que o sinergismo é diferenciado para cada uma das estirpes estudadas.

Por outro lado, em estudo envolvendo a interação de FMA, rizóbio, actinomicetos e soja, em casa de vegetação, Pereira et al. (1991) observaram, trabalhando com inóculos de ACT- 
78 (antagônico a estirpe BR-33 - B. japonicum), Glomus etunicatum, e estirpe BR-33, que a inoculação de actinomicetos reduziu a do rizóbio e aumentou o rendimento de matéria seca da parte aérea. A colonização micorrízica foi reduzida na presença do rizóbio e completamente inibida com a inoculação do actinomiceto. Este resultado leva à suspeição de que o isolado de actinomiceto ACT-78 desenvolva antibiose para FMA do gênero Glomus spp., haja vista que, coincidentemente, sua interação com o FMA Glomus clarum neste trabalho tem uma tendência ao antagonismo, o que precisa ser melhor investigado.

A modelagem da variável DARS envolveu a participação das interações entre os fatores 1 e 2 ; e 1 e 3 , sendo os tratamentos contendo somente $B$. japonicum e inóculo misto [B. japonicum + B. elkanii] os que produziram médias diferentes para as plantas inoculadas com o fungo "Glomus clarum", representando a interação Fator1*Fator2 (Figura 2A); já as plantas tratadas com "Isolado ACT - 78" e "sem actinomicetos" também apresentaram médias de DARS distintas para as plantas de soja que receberam a inoculação do fungo "Gigaspora margarita" (Figura 2B1 e 2B2), o que representa a interação Fator1*Fator3.

Constata-se, então, a influência dos isolados de FMA G. margarita e G. clarum na densidade populacional de actinomicetos na rizosfera de soja cv. Seridó (Figuras 2A, 2B1, $2 \mathrm{~B} 2$ e $2 \mathrm{C}$ ). Este efeito se torna mais significativo na interação entre o isolado FMA de G. clarum mais a mistura de rizóbio (BR33-B. japonicum + BR 29-B. elkanii) - Figura 2A e na interação entre o FMA G. margarita e o isolado de actinomiceto
ACT-78 (Figura 2C) em relação às plantas que não receberam actinomicetos, para esta variável analisada.

De acordo com Cardoso \& Nogueira (2007) a presença de micro-organismos na rizosfera, pode aumentar a exsudação radicular. Micro-organismos como o rizóbio e fungos micorrízicos que são simbióticos, aumentam, quantitativa e qualitativamente, a exsudação, visto que esses microorganismos influenciam diretamente o crescimento da planta e, portanto, sua fisiologia (Andrade, 1999).

Os fungos micorrízicos arbusculares e micro-organismos na rizosfera podem influenciar seu mútuo desenvolvimento e exercer efeitos combinados sobre o crescimento das plantas (Meyer \& Linderman, 1986).

A inoculação dos isolados de FMA influenciou significativamente a densidade de actinomicetos na rizosfera das plantas de soja, ou seja, o estabelecimento de uma micorrizosfera, constatado por vários autores que mostram que o estabelecimento da micorriza arbuscular estabelece mudanças tanto quantitativas quanto qualitativas nas populações microbianas na rizosfera ou micorrizosfera (Azcón-Aguilar \& Barea, 1996). Mudanças qualitativas na comunidade microbiana da rizosfera induzida pelos FMA podem ser causadas por efeitos indiretos na fisiologia do hospedeiro e mudanças na exsudação das raízes (Meyer \& Linderman, 1986) ou exsudatos fúngicos (Paulitz \& Linderman, 1989).

Grande número de bactérias, actinomicetos e fungos é encontrado formando interações e associado a estruturas do
A.

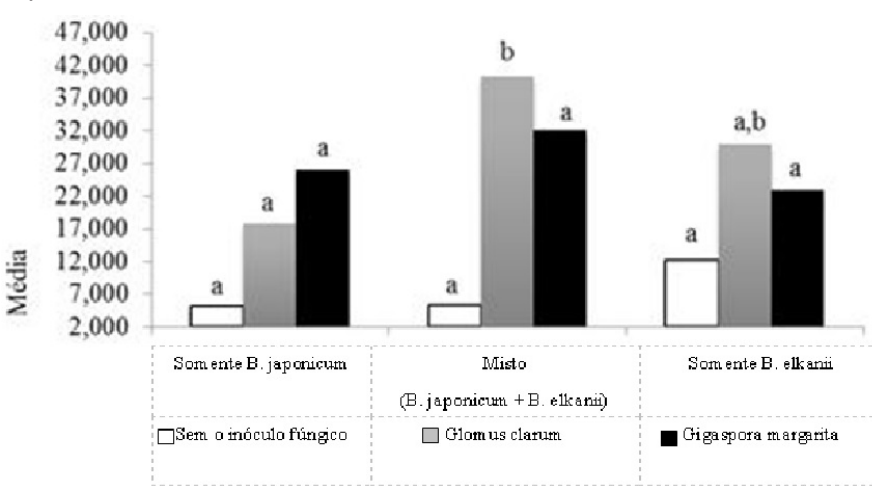

B2.

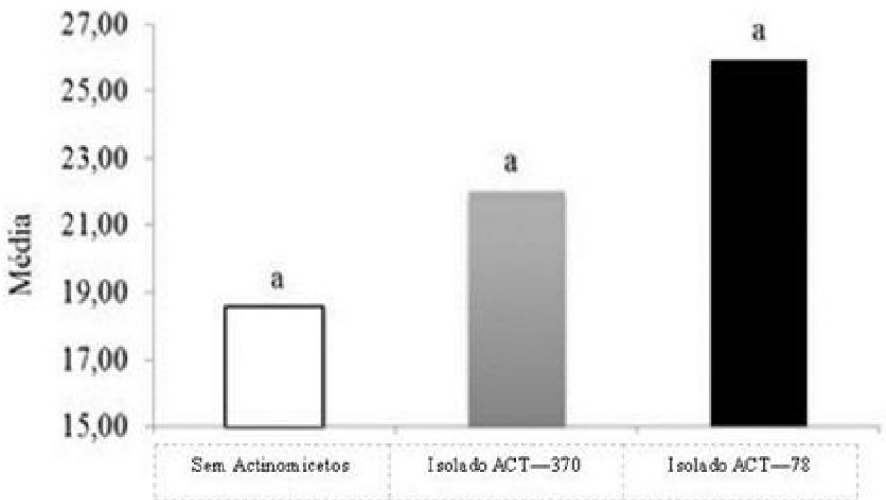

B1.

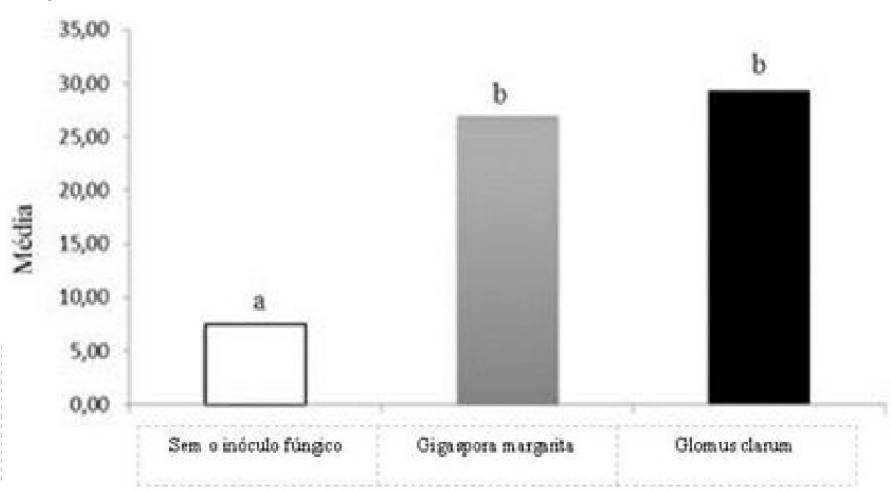

C.

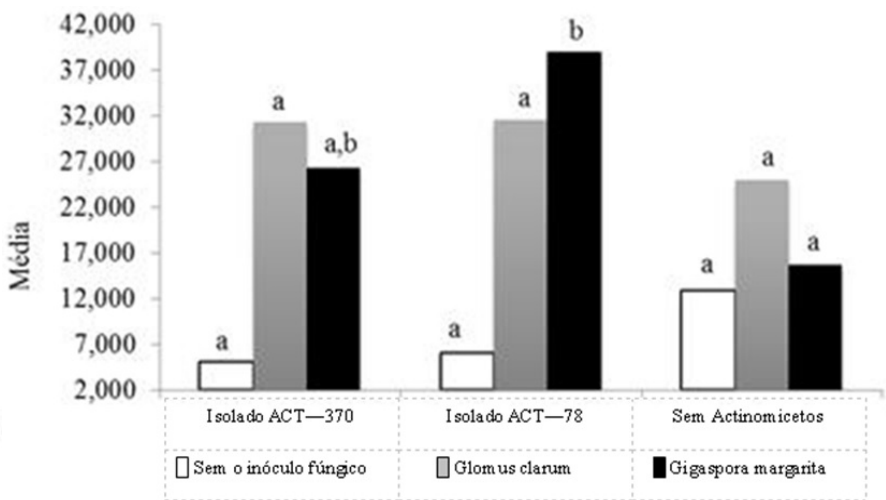

Obs.: Médias seguidas de mesma letra entre colunas de mesma cor, não diferem entre si pelo Teste de Tukey a 5\%;

Figura 2. Comparações múltiplas das médias da variável DARS para a interação entre os fatores 1 e 2 do experimento (A), da variável DARS para os fatores 1 (B1) e 3 (B2) do experimento e da variável DARS para a interação entre os fatores 1 e 3 do experimento $(C)$ 
fungo FMA. Aspecto interessante neste sentido é que algumas bactérias Pseudomonas aderem à hifa micorrízica que sugere ser um veículo para a colonização da raiz por essas bactérias (Bianciotto et al., 2000). As hifas externas dos FMA também podem servir de substrato microbiano sendo consumidas (Andrade, 1999) ou ainda os esporos podem ser parasitados perdendo sua viabilidade (Siqueira et al., 1984). Bianciotto et al. (2001) descreveram polissacarídeos extracelulares envolvidos na adesão de Azospirillum e Rhizobium na estrutura micorrízica.

\section{CONClusões}

1. A inoculação isolada de fungos micorrízicos influenciou, de modo significativo, a biomassa de parte aérea seca (BPAS) e de raiz seca (BRS), a relação entre BPAS/BRS, número de nódulos, a biomassa de nódulos secos e a densidade de actinomicetos na rizosfera de soja.

2. A estirpe BR 29 de Bradyrhizobium elkanii quando inoculada sozinha e o isolado Actinomiceto-370 de Streptomyces proporcionaram um número maior de nódulos. Houve efeito antagônico do isolado ACT-78 na biomassa de nódulos secos.

3. Foram observados efeitos sinergísticos dos fungos micorrízicos arbusculares dos isolados de Streptomyces e dos rizóbios.

\section{Agradecimentos}

À CAPES, pelo auxílio financeiro no período inicial do Curso de Mestrado na UFRRJ; à Dra. Maria Cristina Prata Neves, pela orientação dos trabalhos realizados no CNPAB/ EMBRAPA e ao Dr. João Carlos Pereira (In memoriam), à Dra. Eliane Maria Ribeiro da Silva e ao Dr. Carlos Alberto Tuão Gava, pelo apoio recebido durante a pesquisa e ao Prof. Dr. Joab de Oliveira Lima, do Departamento de Estatística da UFPB pelo apoio nas análises estatísticas e pelas sugestões no trabalho; enfim, ao CNPAB/EMBRAPA pela infraestrutura necessária à execução da pesquisa.

\section{Literatura Citada}

Alves, B. J. R.; Boddey, R. M.; Urquiaga, S. The success of BNF in soybean in Brazil. Plant and Soil, v.252, p.1-9, 2003.

Andrade, G. Interacciones microbianas en la rizosfera. In: Siqueira, J. O.; Moreira, F. M. S.; Lopes, A. S.; Guilherme, L. R. G.; Faquim, V.; Furtini-neto, A. E.; Carvalho, J. G. (ed.). Inter-relação fertilidade, biologia do solo e nutrição de plantas. Lavras: SBCS/UFLA, 1999. p.551-575.

Azcón, C.; Barea, J. Interacciones de las micorrizas arbusculares con microorganismos de la rizosfera. En: Guerrero, E. Micorrizas: Recurso biológico del suelo. Bogotá: Fondo FEN, 1996. p.47-68.

Barea, J. M.; Pozo, M. J.; Azcón, R.; Azcón-Aguilar, C. Microbial co-operation in the rhizosphere. Journal of Experimental Botany, v.56, p.1761-1778, 2005.
Bianciotto, V.; Andreotti, S.; Balestrini, R.; Bonfante, P.; Perotto, S. Mucoid mutants of the biocontrol strain Pseudomonas fluorescens CHA0 show increased ability in biofilm formation on mycorrhizal and nonmycorrhizal carrot roots. Molecular Plant Microbe Interactions, v.14, p.255-260, 2001

Bianciotto, V.; Lumini, E.; Lanfranco, L.; Minerdi, D.; Bonfante, P.; Perotto, S. Detection and identification of bacterial endosymbionts in arbuscular mycorrhizal fungi belonging to the family Gigasporaceae. Applied and Environmental Microbiology., v.66, p.4503-4509, 2000.

Boddey L. H.; Hungria, M. Phenotypic grouping of Brazilian Bradyrhizobium strains which nodulate soybean. Biology and Fertility of Soils, v.25, p.407-415, 1997.

Cardoso, E. J. B. N.; Nogueira, M. A. A rizosfera e seus efeitos na comunidade microbiana e na nutrição de plantas. In: Silveira, A. P. D.; Freitas, S. S. (org.). Microbiota do solo e qualidade ambiental. Campinas: Instituto Agronômico, 2007. p.78-96.

Daniels-Hylton, K. D. M.; Ahmad, M. H. Inoculation response in kidney beans (Phaseolus vulgaris, L.) to vesicular-arbuscular mycorrhizal fungi and rhizobia in non-sterilized soil. Biology and Fertility of Soils, v.18, p.95-98, 1994.

Fracchia, S.; Sampedro, I.; Scervino, J. M; , García-Romera, I.; Ocampo, J. A.; Godeas, A. Influence of saprobe fungi and their exudates on arbuscular mycorrhizal symbiosis. Symbiosis, v.36, p.169-182, 2004.

Franco, A. A.; Döbereiner, J. Especificdade hospedeira na simbiose com Rhizobium - feijão e influência de diferentes nutrientes. Pesquisa Agropecuária Brasileira, v.2, p.467474, 1967.

Gottlieb, D. General consideration and implications of the actinomycetales. In: Sykes, G.; Skinner, F. A. (ed.). Actinomycetales: Characteristics and practical importance. London: Academic Press, 1973. p.1-10.

Melchiorre, M.; Luca, M. J.; Anta, G. G.; Suarez, P.; Lopez, C.; Lascano, R.; Racca, R. W. Evaluation of bradyrhizobia strains isolated from field-grown soybean plants in Argentina as improved inoculants. Biology and Fertility of Soils, v.47, p.81-89, 2011.

Meyer, J. R.; Linderman, R. G. Selective influence on populations of rhizosphere or rhizoplane bacteria and actinomycetes by mycorrhizas formed by Glomus fasciculatum. Soil Biology Biochemistry, v.18, p.191-196, 1986.

Moreira, F. M. S.; Siqueira, J. O. Microbiologia e bioquímica do solo. 2.ed. Lavras: UFLA, 2006. 729p.

Nambiar, P. T. C.; Anjaiah, V. Competition among strains of Bradyrhizobium and vesicular-arbuscular mycorrhizae for groundnut (Arachis hypogaea L.) root infection and their effect on plant growth and yield. Biology and Fertility of Soils, v.8, p.311-318, 1989.

Neves, M. C. P.; Rumjanek, N. G. Ecologia do Rizóbio em solos tropicais. Seropédica: Embrapa CNPAB, 1996. 27p. Documentos 23 
Neves, M. C. P.; Rumjanek, N. G. Diversity and adaptability of soybean and cowpea rhizobia in tropical soils. Soil Biology Biochemistry, v.29, p.889-895, 1997.

Paulitz, T. C.; Linderman, R.G. Interactions between fluorescent pseudomonads and VA mycorrhizal fungi. New Phytologist, v.113, p.37-45, 1989.

Pereira, J. C.; Neves, M. C. P.; Drozdowicz, A. Influência da antibiose exercida por actinomicetos às estirpes de Bradyrhizobium spp, na nodulação da soja. Pesquisa Agropecuária Brasileira, v.34, p.99-108, 1999.

Pereira, J. C.; Paula, M. A.; Guerra, J. G. M.; Monteiro, E. M. S. Influência de actinomicetos no sistema simbiótico de Glycine max - Bradyrhizobium japonicum - Glomus etunicatum em solos sob cerrado. In: Reunião Brasileira sobre Micorrizas, 4, 1991, Mendes, Resumos... Mendes: Embrapa CNPBS 1991. 189p.

Santos, C. E. R. S.; Freitas, A. D. S.; Vieira, I. M. M. B.; Colaço, W. Fixação Simbiótica do $\mathrm{N}_{2}$ em leguminosas tropicais. In: Figueiredo, M. V. B.; Burity, H. A.; Stamford, N. P.; Santos, C. E. R. S. Microrganismos e agrobiodiversidade: $\mathrm{O}$ novo desafio para a agricultura. Guaíba: Agrolivros, 2008. p.17-41.

Satheeja, S. V. Jebakumar, S. R. D. Phylogenetic analysis and antimicrobial activities of Streptomyces isolates from mangrove sediment. Journal of Basic Microbiology, v. 51, p.71-79, 2011.
Siqueira, J. O.; Hubbell, D. H.; Kimbrough, J. W.;Shenck, N. C. Stachiobotrys chartarum antagonistic to azygospores of Gigaspora margarita in vitro. Soil Biology Biochemistry, v.16, p.679-681, 1984.

Siqueira, J. O.; Soarea, C. R. F. S.; Santos, J. G. D.; Schneider, J.; Carneiro, M. A. C. Micorrizas e degradação do solo: caracterização, efeitos e ação recuperadora. In: Tópicos em Ciência do Solo, v.1, p.219-306, 2007.

Vejsadova, H.; Siblikova, D.; Gryndler, M.; Simon, T.; Miksik, I. Influence of inoculation with Bradyrhizobium japonicum and Glomus claroideum on seed yield of soybean under greenhouse and field conditions. Journal of Plant Nutrition, v.16, p.619-629, 1993.

Vincent, J. M. A Manual for the practical study of root nodule bacteria. Oxford: Blackwell Scientific. 1970. 164p.

Waksman, S. A. The role of antibiotics in nature: perspectives in biology and medicine. Chicago: Chicago University Press, v.4, p.271-286, 1961

Zilli, J. E.; Campo, R. J.; Hungria, M. Eficácia da inoculação de Bradyrhizobium em pré-semeadura da soja. Pesquisa Agropecuária Brasileira, v.45, p.335-338, 2010.

Zilli, J. E.; Valicheski, R. R.; Rumjanek, N. G.; Simões-Araújo, J. L.; Freire Filho, F. R.; Neves, M. C. P. Eficiência simbiótica de estirpes de Bradyrhizobium isoladas de solo do Cerrado em caupi. Pesquisa Agropecuária Brasileira, v.41, p.811818, 2006. 